\section{Hemispheric infarction after herpes zoster ophthalmicus}

To the Editor: Kuroiwa and Furukawa' reported a case of herpes zoster ophthalmicus followed by contralateral hemiparesis with a lesion of diminished density in the internal capsule on CT. We recently encountered a case with strikingly similar CT-abnormalities, which prompted us to this report.

Case report. This 66-year-old right-handed male noticed on July 11, 1981 a vesicular rash on his left forehead and round his left eye, which was swollen and painful. About 2 weeks later the blisters had grossly disappeared and he went on vacation abroad. On August 1, 1981 he noticed a right facial weakness and difficulty in talking. These signs disappeared in about 1 hour; 2 hours later he again noticed a right facial weakness and weakness of his right arm that subsided after about 3 hours but did not completely disappear. After admission to an other hospital in Yugoslavia, he was transferred 3 days later to this hospital. His previous history revealed a pneumonia 24 years ago. On admission he was alert, subfebrile $\left(37.8^{\circ} \mathrm{C}\right)$, RR $150 / 70$, pulse 79 /minute. Small cutaneous scars were seen around his left eye and on his left forehead. There was a slight injection of the left eye. There were no other general abnormalities.

On neurologic examination he was alert, but disoriented to time and space. He had a tendency to confabulations. The palpebral fissure was wider on the right and the right nasolabial fold was less prominent. There was a right homonymous hemianopia. There was a hypesthesia and a hypoalgesia on the right side of the face. Corneal reflexes appeared to be equal. On protrusion the tongue deviated to the right. There was a slight proximal weakness of the right arm and a slightly diminished touch and pinprick perception over the right arm and hand. There were no other neurologic abnormalities.

The ESR was $10 \mathrm{~mm}$, Age (CF 0.44) and leukocytes 9,600 with $67 \%$ polynuclear cells, $70 \%$ lymphocytes, and $7 \%$ monocytes. Glucose, electrolytes, renal, and liver function were normal. Urinalysis showed no abnormalities. Vitamins $B_{1}, B_{12}$, and folic acid levels were normal. VDRL and TPHA were negative. Serology on antinuclear antibodies was negative. The ECG showed no abnormalities. X-rays of the skull showed a calcified pineal gland. The chest $\mathrm{x}$-ray was normal.

Serology showed increased titers on complement fixation reaction on herpes zoster (1:128). The spinal fluid was clear and colorless with an opening pressure of 9 cm $\mathrm{H}_{2} \mathrm{O}$, protein $0.48 \mathrm{~g} / \mathrm{l}$, glucose $3.3 \mathrm{mmol} / \mathrm{l}$, cells: $7 / 3$ polynuclear cells, 80/3 monocytes, and 6/3 erythrocytes. Immunofluorescence was negative. The IgG index was increased: 1.38 (IgG in CSF $39 \mathrm{mg} / \mathrm{ml}$, albumin $337 \mathrm{mg}$ / $\mathrm{ml}$, IgG serum $5.6 \times 10^{3} \mathrm{mg} / \mathrm{l}$, and albumin $67 \times 10^{3}$ $\mathrm{mg} / \mathrm{l})$.

The EEG showed bilateraly diffused theta waves (4$7 / \mathrm{sec}$ ) and a left frontal temporal focus of theta waves $(4-5 / \mathrm{sec})$. The CT scan showed symmetric nondilated ventricles. There was a small hypodense zone in the left internal capusle. After contrast there was only a slight enhancement at the backside of this hypodense area, consistent with some hypervascularization (figure). A radionucleide scan of the brain did not show any

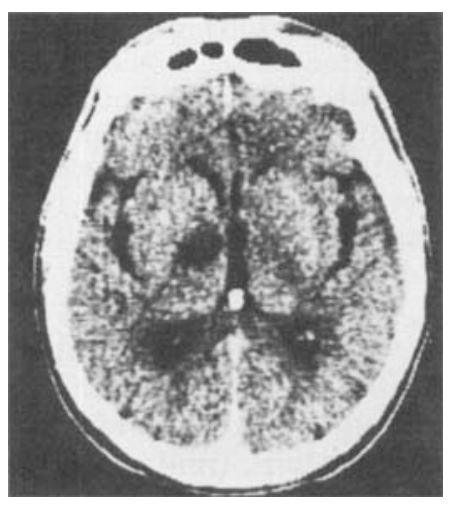

Figure. Slight

enhancement (after contrast) posterior to hypodense area.

abnormalities. Kuroiwa and Furukawa ${ }^{1}$ drew attention to the arteritis of the proximal part of the middle cerebral artery on angiography and a low density lesion on CT in the left internal capsule.

Although we chose not to perform an angiography ${ }^{2}$ we also found a hypodense zone in the internal capsule. Because of this localization, together with the medical history, we believe that a vasculitis of the lenticulostriate arteries was present in our case as well. Kuroiwa and Furukawa supported the theory that gasserian ganglionitis led to a secondary arteritis of the nearby proximal middle cerebral artery and subsequently of the lenticulostriate arteries. However, a necessary step in this process is the involvement of (dural and) leptomeninges separating the ganglion gasseri from the middle cerebral artery. The pleocytosis and increased IgG in the CSF as found in both cases are pointing to meningitis or meningoencephalitis. Subsequently this easily may cause a vasculitis of nearby arteries. In this way the development of a meningitis (meningoencephalitis) is not in contrast with and might even be regarded as an extra support for their theory.

\section{References}

1. Kuroiwa Y, Furukawa R. Hemispheric infarction after herpes zoster ophthalmicus: computed tomography and angiography. Neurology (Ny) 1981;31:1030-2.

2. Pratesi R, Freemon FR, Lowry JL. Herpes zoster ophthalmicus with contralateral hemiplegia. Arch Neurol 1977;34:640-1.

$$
\begin{array}{r}
\text { Ch.J Vecht, } \\
\text { J.J. v.d. Sande }
\end{array}
$$

Municipal Hospital Slotervaart, Louwesweg, Amsterdam, The Netherlands

To the Editor: In their case report on delayed contralateral hemiparesis in a patient with herpes zoster ophthalmicus, Kuriowa and Furukawa' ${ }^{\prime}$ attribute the stroke to granulomatous angiitis, which Linnemann and Alvira $^{2}$ ascribed to contiguous invasion of the vessel 
wall by herpes zoster virus. We recently cared for a patient with a similar syndrome.

Case report. A 69-year-old woman with resected colon carcinoma on chemotherapy developed left herpes zoster ophthalmicus in April 1981. In late June 1981, she was transferred to our hospital in a semistuporous state, with right hemiparesis, aphasia, and bilateral basal ganglia features, more marked on the right. CT revealed bilateral basal ganglia enhancing lesions. CSF revealed 14 WBCs (all mononuclear), protein $55 \mathrm{mg}$ per deciliter, and glucose $84 \mathrm{mg}$ per deciliter. After treatment with anticholinergic drugs she alerted to a degree only to worsen again 2 weeks later. Cerebral arteriography could not be performed because of the patient's inability to cooperate. Repeat CT showed resolving bilateral basal ganglia infarcts and a newer enhancing right frontal infarct. Left temporal brain and meningeal biopsies, light and electronmicroscopy studies, and viral studies were normal. The patient continued to do poorly and was transferred to an extended care facility.

If the delayed contralateral hemiparesis after zoster ophthalmicus is due to viral invasion of the arteries and resultant granulomatous angiitis, one might expect to see the viral particles with electronmicroscopic examination of the affected vessels. That being the case, with proper handling and culture techniques, herpes zoster virus should be recovered. This obviously means active infection and if the arteritis is to be arrested then therapy must be directed towards the replicating virus.

Acyclovir, a guanine derivative, has recently been reported to be effective against herpes simplex and herpes zoster infections. ${ }^{3} 7$ The proposal that granulomatous angiitis in the setting of zoster ophthalmicus is due to viral infection assumes greater importance and significance, for now a treatment aimed at the specific pathophysiology may be available. However, since the complete scenario in a living patient has not yet established the proposed pathophysiology, efforts should be directed at so doing.

When a patient is suspected of having zoster granulomatous angiitis we propose the following: (1) arteriography to establish the diagnosis of arteritis; (2) meningeal biopsy in the vicinity of affected vessels (as demonstrated on arteriography) in hopes of seeing the viral particles in the vessel wall and the virus. Once these criteria are met the patient could be given an antiviral agent, such as acyclovir, to prevent progression of the granulomatous angitis.

Carl F. McComas, M.D. Ludwig Gutmann, M.D.

Department of Neurology West Virginia University Morgantown, $W V$

\section{References}

1. Kuroiwa Y, Furukawa T. Hemispheric infarction after herpes zoster ophthalmicus: computed tomography and angiography. Neurology (Ny) 1981;31:1030-2.
2. Linnemann CC, Alvira MM. Pathogenesis of varicella-zoster angiitis in the CNS. Arch Neurol 1980;37:239-40.

3. Saral R, Burns WH, Laskin OL, Santos GW, Leitman PS. Acyclovir prophylaxis of herpes-simplex virus infections: A randomized, double-blind, controlled trial in bone-marrow transplant recipients. N Engl J Med 1981;305:63-7.

4. Chou S, Gallagher JG, Merigan TC. Controlled clinical trial of intravenous acyclovir in heart-transplant patients with mucocutaneous herpes simplex infections. Lancet 1981;1:1392-4.

5. Mitchell CD, Bean B, Gentry SR, Boen JR, Groth KE, Balfour $\mathrm{HH}$. Acyclovir therapy for mucocutaneous herpes simplex infection in immunocompromised patients. Lancet 1981;1:1389-92.

6. Biron KK, Elion GB. In vitro susceptibility of varicellazoster virus to acyclovir. Antimicrob Agents Chemother 1980;18:443-7.

7. Elion GB, Furman PA, Fyfe JA, deMiranda P, Beauchamp $\mathrm{L}$, Schaeffer $\mathrm{HJ}$. Selectivity of action of an antiherpetic agent, 9-2(2-hydroxyethyoxymethyl) guanine. Proc Natl Acad Sci USA $1977 ; 74: 5716-20$.

Reply from the Authors: We appreciate the comments of Drs. Vecht and Sande. They reported a 66-year-old man who suffered right hemiparesis 3 weeks after the onset of left herpes zoster ophthalmicus (HZO). The CT abnormalities were similar in their patient and ours. We believe that both cases had an identical pathologic process: a hemispheric stroke due to granulomatous angiitis.

In our paper, ${ }^{1}$ we mentioned that CSF lymphocytic pleocytosis is frequent in patients with delayed hemiparesis contralateral to $\mathrm{HZO}$. We agree that CSF pleocytosis in those cases may reflect localized meningitis, contributing to subsequent vasculitis of nearby arteries. CSF pleocytosis is not against our theory.

We are pleased that Drs. McComas and Gutmann found our case report of interest. In our review of the literature on ophthalmic herpes zoster with delayed contralateral hemiplegia or hemiparesis, most patients were alert or only transiently confused. ${ }^{1}$ The patient of Drs. McComas and Gutmann is unique in that she was in a semistuporous state. Serial CT revealed bilateral basal ganglia infarcts and a right frontal infarct. It seems that the cerebral infarcts in their case were widely distributed throughout the cerebral hemispheres. We believe that neuropathologic changes in their case are similar to the autopsy findings in two fatal cases reported previously. ${ }^{2,3}$ One case of Rosenblum and Hadfield (case $2)^{2}$ and one of Kolodny et al (case 4$)^{3}$ had right ophthalmic herpes zoster and delayed left hemiplegia. Neuropathologic findings in both cases showed extensive cerebral infarcts, involving hemispheric white matter, basal ganglia, thalamus, and brainstem. The diseased blood vessels in both cases bore characteristic evidence of granulomatous angiitis of the brain in varying stages of development. Therefore neurologic signs in the patient of Drs. McComas and Gutmann can reasonably be ascribed to the granulomatous angiitis with consequent vascular thrombosis.

Drs. McComas and Gutmann proposed employment of an antiviral agent, such as acyclovir, to treat herpes zoster granulomatous angiitis, provided that an arter- 
iogram and a meningeal biopsy supported viral invasion of the arteries with resultant granulomatous angiitis. We do believe that such a therapeutic policy can be justified as an experimental study.

Yoshiyuki Kuroiwa, M.D.

Department of Neurology, Institute of Brain Research, Faculty of Medicine. University of Tokyo.

Tetsuo Furukawa, M.D.

Department of Neurology Tokyo Medical and Dental University, Tokyo, Japan

\section{References}

1. Kuroiwa Y, Furukawa T. Hemispheric infarction after herpes zoster ophthalmicus: computed tomography and angiography. Neurology (Ny) 1981;31:1030-2.

2. Rosenblum WI, Hadfield MG. Granulomatous angiitis of the nervous system in cases of herpes zoster and lymphosarcoma. Neurology (Minneap) 1972;22:348-54.

3. Kolodny EH, Rebeiz JJ, Caviness CVS Jr, et al. Granulomatous angiitis of the central nervous system. Arch Neurol 1968;19:510-24.

\section{Measurement of long-chain acylcarnitine}

To the Editor: Biochemical diagnosis of carnitine deficiencies is based on measurement of carnitine and its esters in plasma and tissue. Carnitine deficiencies represent a spectrum of diseases ${ }^{1}$ in which one can identify (a) muscle carnitine deficiency with low levels of carnitine in skeletal muscle and normal plasma carnitine; (b) systemic or generalized carnitine deficiency with low carnitine content in muscle, liver, and plasma; ${ }^{3}$ and (c) secondary forms of carnitine deficiency with low carnitine in tissues and plasma and abnormal distribution of carnitines. ${ }^{4}$ Since the free carnitine content in plasma is normal in muscle carnitine deficiency and low in systemic carnitine deficiency, measurement of free plasma carnitine may differentiate the two forms.' Diagnosis of both forms of carnitine deficiency requires determination of carnitine in muscle and liver biopsies. Generally, carnitine is measured as free carnitine and carnitine esters representing the sum of short-chain and long-chain carnitines. Short-chain carnitines fluctuate with serum ketones during fasting, but plasma levels of long-chain carnitines are stable."

We measured plasma levels of free, short-chain, and long-chain acylcarnitines in 24 controls with different neuromuscular disorders, aged 2 to 50 years, and in 7 patients with different forms of carnitine deficiency (table). One patient with systemic carnitine deficiency had a plasma free carnitine content that was near normal. Patients with both systemic and muscular forms of carnitine deficiency had marked increases of long-chain acylcarnitines. In each patient with carnitine deficiency the percentage of long-chain acylcarnitines was significantly greater $(p<0.001)$ than in the controls. The lowest value found in a patient ( $4.9 \mathrm{nmol}$ per milliliter) was $213 \%$ of the highest value found in controls $(2.3$ nmol per milliliter). The mean value of long-chain acylcarnitines in muscular forms of carnitine deficiency was $12.9 \pm 1.8 \mathrm{SD} \%$ of the total carnitine; in systemic forms of carnitine deficiency, the mean value of long-chain acylcarnitines was $36.1 \pm 9 \mathrm{SD} \%$ of the total carnitine.

We conclude that the measurement of only the free carnitine fraction in plasma is less useful than measurement of long-chain acylcarnitines in the diagnosis for both muscular and systemic carnitine deficiency.

M. Rimoldi, M.S. S. DiDonato, M.D.

Laboratory of Neurometabolic Diseases Istituto Neurologico "C.Besta" Milano, Italy

Table. Plasma carnitines

\begin{tabular}{|c|c|c|c|c|c|}
\hline & Free & Short-chain & Long-chain & Total & $\begin{array}{c}\text { Long-chain } \\
\% \text { total }\end{array}$ \\
\hline Controls & $\begin{array}{c}37.0 \pm 12.2 \\
(23-52)\end{array}$ & $\begin{array}{l}4.2 \pm 1.9 \\
(2.8-8.4)\end{array}$ & $\begin{array}{l}1.5 \pm 0.4 \\
(0.9-2.3)\end{array}$ & $\begin{array}{c}41.4 \pm 12.3 \\
(26.2-60.0)\end{array}$ & $\begin{array}{l}4.1 \pm 1.0 \\
(2.3-6.0)\end{array}$ \\
\hline \multicolumn{6}{|c|}{ Muscular form patients } \\
\hline No 1 & 34.2 & 6.1 & 4.9 & 45.2 & 10.8 \\
\hline No 2 & 45.2 & 2.4 & 7.5 & 55.1 & 13.6 \\
\hline No 3 & 36.3 & 14.9 & 8.5 & 59.7 & 14.2 \\
\hline \multicolumn{6}{|c|}{ Systemic form patients } \\
\hline No 4 & 30.1 & 5.3 & 10.5 & 45.9 & 22.9 \\
\hline No 5 & 14.4 & 3.0 & 10.7 & 28.1 & 38.1 \\
\hline No 6 & 8.4 & 5.2 & 10.0 & 23.6 & 42.4 \\
\hline No 7 & 7.2 & 8.3 & 10.8 & 26.3 & 41.0 \\
\hline
\end{tabular}




\section{References}

1. Di Mauro S, Trevisan C, Hays A. Disorders of lipid metabolism in muscle. Muscle Nerve 1980;3:369-88

2. Engel AG, Angelini A, Nelson AR. Identification of carnitine deficiency as a cause of human lipid storage myopathy. In: Milhorat AT, ed. Exploratory concepts: II. control mechanism in development and function of muscle. Amsterdam: Excerpta Medica, 1974:601-7.

3. Karpati G, Carpenter S, Engel AG, et al. The syndrome of systemic carnitine deficiency. Neurology (Minneap) 1975;25:16-24.

4. Di Donato S, Cornelio F, Balestrini MR, et al. Mitochondrialipid glicogen myopathy, hyperlactacidemia and carnitine deficiency. Neurology (Ny) 1978;28:1110-6.

5. Di Donato S, Peluchetti D, Rimoldi M, et al. Ketogenic response to fasting in human carnitine deficiencies. Clin Chim Acta 1980;100:209-14

\section{Erythrocyte membrane studies}

To the Editor: In previous studies ${ }^{1.2}$ we reported decreased intramembranous particle density in erythrocytes from patients with Duchenne muscular dystrophy. We have repeated these studies to see whether these freeze-fracture abnormalities are preferentially located in young or old erythrocytes. No differences were found between controls and young or old erythrocytes from three patients. This result prompted a review of our original material. Replicas from four of the original cases plus appropriate controls were rephotographed and counted in triplicate. No statistically significant differences were found between normal and Duchenne. We are therefore unable to confirm our original report that freeze-fracture abnormalities are present in $\mathrm{Du}$ chenne erythrocytes.

Yoshihiro Wakayama, M.D. Kenneth Fischbeck, M.D. Eduardo Bonilla, M.D. Donald L. Schotland, M.D. Department of Neurology
University of Pennsylvania Philadelphia, PA

\section{References}

1. Wakayama Y, Hodson A, Pleasure D, Bonilla E, Schotland DL. Alteration in erythrocyte membrane structure in Duchenne dystrophy. Ann Neurol 1978;4:253-6.

2. Wakayama Y, Hodson A, Bonilla E, Pleasure D, Schotland DL. Freeze-fracture studies of erythrocyte plasma membrane in human neuromuscular disease. Neurology (Ny) $1979 ; 29: 670-5$.

\section{Intracranial hemorrhage associated with amphetamine use}

To the Editor: I report another case of intracranial hemorrhage (ICH) following the intake of an amphet- amine-like substance, similar to those reported by D'Souza and Shraberg.'

Case report: According to the family and the history subsequently obtained, this 24-year-old right-handed man had taken two tablets of "Black Mollies" (illegal amphetamine tablets) several hours before admission. He came home complaining of headaches and nausea, vomited, lapsed into deep stupor, and was brought to the hospital. For four years, he had been taking phenytoin and phenobarbital for a posttraumatic seizure disorder. His blood pressure was $150 / 95 \mathrm{~mm} \mathrm{Hg}$; he was afebrile, his pulse fluctuated between 45 to 60 per minute and he was breathing on his own. He was in deep stupor, with appropriate responses to deep painful stimuli, and there was a left hemiparesis. His eyes tended to drift to the right. The pupils were normal. There was a $\mathrm{Ba}$ binski sign on the left. The rest of the examination was otherwise normal. CT revealed a large deep intracerebral hematoma on the right side with a shift to the left (figure 1). Routine blood was normal. A right cerebral angiogram revealed a deep thalamic avascular mass but no aneurysm or arteriovenous malformation. The hematoma was evacuated surgically. Postoperatively, there was a dense left hemiplegia and moderate expressive aphasia. In the next few weeks his speech im-

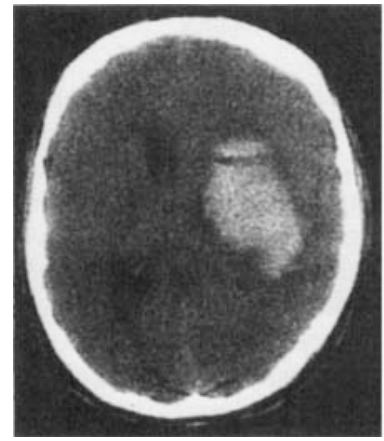

Figure 1.

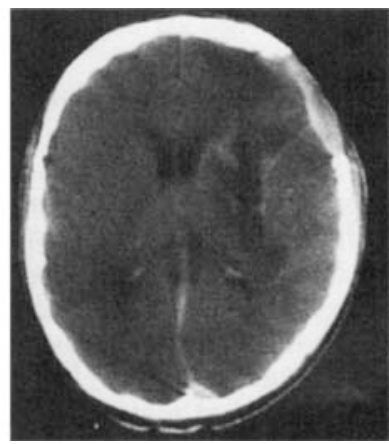

Figure 2. proved but the left hemiplegia persisted. CT revealed a resolving intracerebral hematoma (figure 2).

This case is similar to those described by D'Souza and Delaney. ${ }^{2} \mathrm{~A}$ small oral dose amphetamine had a devastating result. There was mild hypertension in our case. In all of these patients, amphetamine or similar substances may cause transient high blood pressure that causes a "typical" hypertensive intracerebral hemorrhage. However, there are many street drug "lookalikes" that include contaminants and chemicals with amphetamine-like actions which could also be responsible.

\section{Dinesh Shukla, M.D}

Smithtown, NY

\section{References}

1. D'SouzaT, Shraberg D. Intracranial hemorrhage associated with amphetamine use. (letter to the Editor). Neurology 
(Ny) $1981 ; 31: 922-3$.

2. Delaney $P$, Estes M. Intracranial hemorrhage with amphetamine abuse. Neurology ( $\mathrm{Ny}$ ) 1980;30:1125-8;1981. 31:1059-60

Reply from the Authors: The case reported by Dr. Shukla clearly demonstrates the increasing incidence of drug-related neurologic complications in young adults. It also stresses the risks attendant with even occasional drug abuse. The neurologic complications of amphetamine abuse are well known; to state that unknown chemical contaminants with an amphetamine-like action may be responsible for the neurologic symptoms is speculation and must be substantiated by toxicology studies or efforts to determine what these contaminants might be.

Terence D'Souza, M.D. David Shraberg, M.D.

Department of Neurology and Psychiatry Tulane University School of Medicine New Orleans, LA

\section{Progressive supranuclear palsy}

To the Editor: The inference that progressive supranuclear palsy (PSP) is a disorder of the serotonergic system, based on the clinical efficacy of methysergide, cannot be accepted. ${ }^{1}$ Serotonin antagonism is but one action of methysergide. Another action that is attractive in explaining the successful response of PSP to methysergide relates to a direct influence of the drug and its metabolites on dopaminergic receptors.

Lamberts and McLeod have presented compelling evidence that methysergide itself is a dopamine antagonist while its primary metabolite, methergine, is a dopamine agonist. ${ }^{2}$ Prolactin secretion is inhibited by dopamine acting at classical dopamine receptors on pituitary lactotrophs. Under in vitro conditions methysergide blocked dopaminergic inhibition of prolactin secretion from rat anterior pituitary glands. Methergine, under identical conditions, was a potent dopamine agonist. Methergine directly inhibited prolactin secretion by about $90 \%$ and this action was reversed by the dopamine antagonist, haloperidol.

The dopamine antagonist and agonist properties of methysergide and methergine, respectively, were also apparent after parenteral administration of methysergide. Fifteen minutes after injection, prolactin secretion was refractory to dopaminergic inhibition reflecting the probable action of methysergide as a dopamine antagonist. Four hours after a single dose of methysergide prolactin secretion was inhibited but could be restored to normal by prior treatment with haloperidol. This supported the in vitro observation suggesting that biologic transformation of methysergide to methergine had generated an agent that had dopamine agonist properties.

Of course, the neuroendocrine regulation of prolactin secretion may involve different dopamine receptors than elsewhere in the brain but it is at least possible that the beneficial effects of methysergide on PSP could be mediated in part by dopaminergic actions of methergine as noted above. It is prudent to be conservative in speculations about disease pathophysiology as extrapolated from the clinical response to a drug with multiple actions.

Ivan S. Login, M.D.

Department of Neurology University of Virginia Medical Center Charlottesuille, VA

\section{References}

1. Rafal RD, Grimm RJ. Progressive supranuclear palsy: functional analysis of the response to methysergide and antiparkinsonian agents. Neurology (Ny) 1981;31:1507-18.

2. Lamberts SWJ, MacLeod RM. The interaction of the serotonergic and dopaminergic systems on prolactin secretion in the rat. Endocrinology 1978;103:287-95.

Reply from the Author: I am grateful to Dr. Login for his critique of our efforts to implicate a serotonergic connection in the pathophysiology of progressive supranuclear palsy (PSP); and especially for his caveat against making such inferences on the basis of the clinical response to a drug with multiple actions. There are no knives in neuropharmacology, no drugs which are truly discrete in action; or for which we are even close to having a reasonably complete understanding. Caution is even more necessary when, as in the case of our experience with methysergide in PSP, the response of the drug is not consistent. Some patients respond dramatically to the drug, but others do not.

Because of the complexity of this problem, we could not justify an extensive treatment of the neuropharmacologic issues in our paper. We chose to limit our speculations to just one possible mechanism; not the only one possible (or even, perhaps, the most likely), but the one that we felt was the most interesting. We were intrigued by the conceptualization, by Behrman et al,' that the dystonia of PSP might be based on a pathologic excitation of degenerating neurons. We found merit in exploring the neuropharmacologic corollary of their hypothesis, viz that the distinctive clinical features of this disease were based on pathologic excitation of degenerating raphe neurons that could be reversed by the serotonin antagonist, methysergide. It has become conventional to consider diseases affecting neurochemical systems to be deficiency states; and the therapeutic strategy has been to seek agents to replace depleted neurotransmitter. We felt it was worthwhile to entertain the possibility that, in some disorders, the converse may be true. Even if such speculations prove to be incorrect in PSP, this concept may yet be valid in elucidating the pathophysiology of other degenerative disease, especially those producing dystonia or hyperkinesis.

I agree with Dr. Login that the implication of a possible serotonergic disorder in PSP should not be "accepted"only considered. And, it should be considered as only one aspect of a complex disorder involving the deranged interaction of several neurochemical systems. In this regard I'd like to reemphasize an important finding of 
our study, the impressive clinical synergy of agents with different pharmacologic properties. Some patients who do not respond to methysergide or to antiparkinsonian drugs may improve with a combination of these agents. This finding should not be surprising in a disorder where degeneration is known to involve dopaminergic, serotonergic, and noradrenergic neuron populations. Relative overactivity of acetylcholine also seems likely. In our experience L-DOPA/carbidopa has not been as effective as trihexyphenidyl, and benztropine may be beneficial in some patients. ${ }^{2}$

A better understanding of the role of serotonergic mechanisms in PSP should come as we have the opportunity to test the usefulness of other ergolide agents that are chemically related to methysergide, but which differ in effects on neurochemical systems. We found that bromocriptine (a dopaminergic agonist with less antiserotonergic activity than methysergide) was a useful adjunct when used with methysergide in one patient. A recent report ${ }^{3}$ indicates that it may be beneficial in PSP when used alone; but it does not appear, thus far to be as effective as methysergide. I hope soon to test the efficacy of the ergoline, pergolide, which is a strong agonist of both dopamine and serotonin.

In conducting therapeutic studies, there should be certain ground rules. Many patients may require a combination of drugs to optimize quality of life, or just to live a little longer. The best treatment for any given patient has to be individually tailored and, therefore, long-term trials comparing single agents may not be in the best interests of the patient. Furthermore, withdrawal of a drug to which the patient has responded favorably may be life-threatening; therefore, I have serious reservations as to whether crossover studies can be conducted ethically in this disease (at least in dysphagic patients).

In spite of the limitations placed upon us by our primitive understanding of the relevant neurochemistry, and the ethical limitations placed upon us by the malignant nature of the disease, I remain hopeful that we can learn more about progressive supranuclear palsy that will aid us in our efforts to help affected patients.

Addendum. Two errors appeared in the published paper: p. 1516 , left column, line 33 , should read "..., and neurofibrillary change was not found in two patients (patients 2 and 5);" p. 1516, right column, line 18 should read ... "Although patient 5 was clinically atypical, patient 2 had the classic form of the disease."

Robert D. Rafal, M.D.

Neurological Science Center Good Samaritan Hospital \& Medical Center Portland, $O R$

\section{References}

1. Behrman S, Carroll JD, Janota I, Matthews WB. Progressive supranuclear palsy: clinico-pathologic study of four cases. Brain 1969;92:663-78.

2. Haldeman S, Goldman JW, Hyde J, Prisbram HFW. Progressive supranuclear palsy, computed tomography and re- sponse to antiparkisonian drugs. Neurology (Ny) 1981;31:4425 .

3. Janovic J. L-Dopa resistant parkinsonism due to dopa decarboxylase deficiency. Ann Neurol 1981;10:64-5.

4. Rafal RD, Grimm RJ. Progressive supranuclear palsy: functional analysis of the response to methysergide and antiparkinsonian agents. Neurology (Ny) 1981;31:1507-18.

\section{Interictal psychopathology in patients with ictal fear}

To the Editor: Hermann et al $^{1}$ raise an interesting hypothesis regarding the association of interictal psychopathology with the aura of fear in patients with limbic epilepsy. One of our patients, whose ictal rage was most readily provoked by intra-amygdaloid stimulation, had episodes of intense ictal fear. ${ }^{2.3}$ This often preceded cursive seizures. I wonder if "running attacks" might also be a marker for patients with intense interictal psychopathology?

Vernon H. Mark, M.D., F.A.C.S.

Neurosurgical Service

Harvard Medical School

Boston City Hospital

Boston, MA

\section{References}

1. Hermann BP, Kirkmen S, Schwartz SS, Karnes WE. Interictal psychopathology in patients with ictal fear: a quantitative investigation. Neurology ( $\mathrm{Ny}$ ) 1982;32:7-11.

2. Mark VH, Sweet WH. The role of limbic brain dysfunction in aggression. In: Frazier SH, ed. Aggression (Research Publication, vol 52, Association for Research in Nervous and Mental Disease). Baltimore: Williams \& Wilkins, 1974:186-200.

3. Mark VH, Ervin FR, Sweet WH, Delgado JMR. Remote telemeter stimultion and recording from implanted temporal lobe electrodes. Confin Neurol 1969;31:86-93.

\section{Corrections}

"Sarcoidosis presenting as senile dementia" by G. Cordingley, C. Navarro, J. C. M. Brust, and E. B. Healton, September 1981, p. 1149, table 3. Radiographic ventricular enhancement should be changed to enlargement. The percentage for systemic sarcoidosis $(25 / 35)$ should be $71 \%$.

"Amyotrophic lateral sclerosis and parkinsonian syndromes in high incidence among the Auyu and Jakai people of West New Guinea" by D. Carleton Gajdusek and Andres M. Salazar, February 1982, p. 115, right column, line 2, should read "Clinical findings (table 7). The disease typically begins after a period of overwork or physical exhaustion with dysesthesias and hyperesthesias in the legs." 


\title{
Neurology
}

\author{
Sarcoidosis presenting as senile dementia \\ Neurology 1982;32;919-919-a \\ DOI 10.1212/WNL.32.8.919-a
}

This information is current as of August 1, 1982

Updated Information \& Services

Permissions \& Licensing

Reprints including high resolution figures, can be found at: http://n.neurology.org/content/32/8/919.2.citation.full

Information about reproducing this article in parts (figures,tables) or in its entirety can be found online at: http://www.neurology.org/about/about_the_journal\#permi ssions

Information about ordering reprints can be found online: http://n.neurology.org/subscribers/advertise

Neurology $®$ is the official journal of the American Academy of Neurology. Published continuously since 1951, it is now a weekly with 48 issues per year. Copyright $\odot 1982$ by the American Academy of Neurology. All rights reserved. Print ISSN: 0028-3878. Online ISSN: $1526-632 X$.

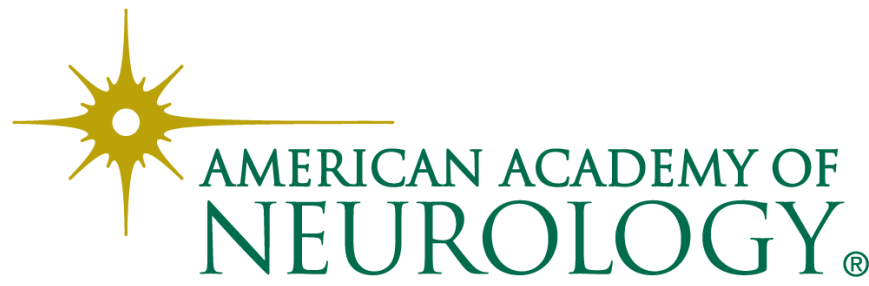

